\title{
At-Home Management Strategies Adopted by Orthodontic Patients During COVID-19 Related Closure of Orthodontic Clinics
}

\author{
Hana Pervez ${ }^{1}$ \\ Maria Khadija Siddiqui ${ }^{2}$ \\ Anam Sattar ${ }^{3}$ \\ Hareem Sultan ${ }^{4}$ \\ Taskeen Khan ${ }^{5}$ \\ Rabiya Haqqui ${ }^{6}$ \\ BDS, FCPS \\ BDS, MPH \\ BDS, FCPS \\ BDS, FCPS \\ BDS \\ BDS
}

OBJECTIVE: The vast spread of COVID-19 not only affected the major businesses of the world but also the health care facilities like dentistry. Due to the unprecedented closure of dental services, on-going orthodontic patients also suffered the brunt. The aim of this study was to assess the at-home management approaches used by the patients to tackle the complications associated with orthodontic treatment.

METHODOLOGY: It was a cross-sectional questionnaire-based study carried out from June 15 to September 15, 2020 in orthodontic OPD of Jinnah Medical and Dental College, Karachi. A total of 300 orthodontic patients, 208 females and 92 males between ages from 15 to 35 years completed a questionnaire on the complications faced by them and management techniques adopted by them during COVID-19 related office closures. Convenient sampling method was used for data collection.

RESULTS: The majority of patients reported in this study were females. Approximately $69.33 \%(n=300)$ of the responders were females and $31 \%$ were males. The highest numbers of complications reported during the lockdown period were loose brackets, loose bands and poking of archwire. The most common at-home hack used was removing the loose bracket/ bands and cutting of free end of archwire with nail cutter like instrument.

CONCLUSION: It is the responsibility of the clinician to keep in touch with their patients during pandemic like situation through telemedicine portal. In case of emergencies, patients should be provided with an adequate amount of information to tackle any complications with ease and without hurting themselves.

KEYWORDS: COVID-19, Pandemic, Orthodontic Emergencies

HOW TO CITE: Pervez H, Siddiqui MK, Sattar A, Sultan H, Khan T, Haqqui R. At-home management strategies adopted by orthodontic patients during covid-19 related closure of orthodontic clinics. J Pak Dent Assoc 2021;30(2):99-102. DOI: https://doi.org/10.25301/JPDA.302.99

Received: 17 September 2020, Accepted: 06 January 2021

\section{INTRODUCTION}

$\mathrm{N}$ o one can deny the negative impact of COVID-19 on social, psychological and economic well-being of the society. ${ }^{1}$ The virus that is

1. Assistant Professor, Department of Orthodontics, Jinnah Medical and Dental College, Karachi.

2. Assistant Professor, Department of Community Dentistry, Jinnah Medical Dental College, Karachi.

3. Consultant, Department of Orthodontics, Zubaida Bani Dental Hospital, Karachi.

4. Assistant Professor, Department of Orthodontics, Dow International Dental College, Dow University Health Sciences, Karachi.

5. FCPS II Trained, Demonstrator, Department of Orthodontics, Dr Irshad-ul-Ebad Khan Institute Oral Health Sciences, Dow University Health Sciences, Karachi.

6. Demonstrator, Department of Orthodontics, Jinnah Medical Dental College, Karachi.

Corresponding author: "Dr. Anam Sattar" < anamsattar9521@ gmail.com > responsible for COVID-19 was initially called as 2019-nCoVand was then termed as syndrome coronavirus 2 (SARS-CoV-2) by the International Committee on Taxonomy of Viruses (ICTV). ${ }^{2}$ The World Health Organization (WHO) declared coronavirus disease as a pandemic on March 11, 2020. ${ }^{3}$

Due to the high rate of transmissibility, the whole world came to a standstill. Major businesses suffered great losses during this once in a life pandemic. Dental profession is as much affected by it as any other field. ${ }^{4}$ According to CDC (Center for Disease Control), the health care profession that is considered to be at the highest risk is the Dental profession. $^{5}$ 
Pervez H/ Siddiqui MK/ Sattar A/ Sultan H/ Khan T/ Haqqui R

Due to abrupt closure of dental services, on-going orthodontic patients also faced lots of uncertainty. The complications that occurred during lockdown like loose bracket, broken bands, ulcers, soreness, impinging wires etc. were had to be dealt with by the patients themselves. ${ }^{6}$ To check their potential and level of knowledge about dealing with difficult situations, a study was designed to check their abilities in the face of an emergency.

The following article briefs about the common orthodontic emergencies that occurred among patients undergoing orthodontic treatment and at- home management strategies implemented by the patients to provide temporary relief and to prevent any further delay in orthodontic treatment.

The objective of this study is to find out the management strategies employed by the on-going orthodontic patients during pandemic related closure of orthodontic services.

\section{METHODOLOGY}

This cross sectional study was conducted from June 15 to September 15, 2020 on orthodontic patients of Jinnah Medical and Dental College, Karachi. Ethical approval was obtained from the ERC ethical review committee, JMDC Approval Number (00036/20) Informed consent was obtained from study participants. A self-administered questionnaire was used in this study. The questionnaire consisted of two parts:

Part 1 elicited demographic data of the participant to determine gender and age.

Part 2 consist of at-home management strategies for complications related to orthodontic treatment.

The filled questionnaires were taken into possession after survey by the researcher and were not left unattended. Every effort was made by the researcher to preserve confidentiality including the following:

- Filled questionnaires will be discarded by paper shredding once research is conducted and will not be used for any other purpose.

- Other researchers will have access to data as long as they agree to preserve the confidentiality.

The sample size was established on the results of the previous study ${ }^{18}$, with $95 \%$ confidence interval and $80 \%$ power of test by using open epi online calculator, the calculated sample size was 300 . Non-probability (convenience) sampling technique was followed. The inclusion criteria includes

- Age of individuals both males and females (15-35 years)

- Voluntary agreement to participate in the study The exclusion criteria includes

- Individuals with syndromes like cleft lip and palate
At-home management strategies adopted by orthodontic patients during COVID-19 related closure of orthodontic clinics

- Individuals aged below $15 y$ years

- Individuals aged above 35 years

The distribution of responses was presented as frequency and percentages. Data were tabulated in excel, and descriptive statistics were performed by using SPSS 21 (statistical package for social sciences).

\section{RESULTS}

A total of 300 orthodontic patients responded to this survey. Approximately $69.33 \%(\mathrm{n}=300)$ of the responders were females and $31 \%$ were males. (Table1), (Fig 1). The

Figure 1: Distribution of sample

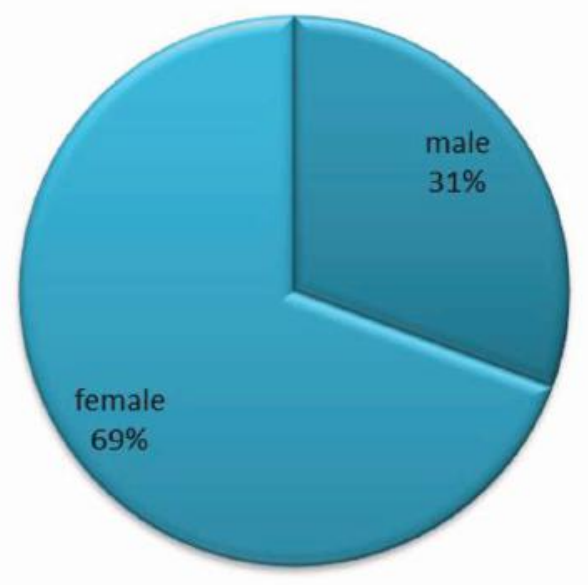

Table 1: Gender distribution of patients

\begin{tabular}{|l|l|l|}
\hline GENDER & Responders & Percentage \\
\hline FEMALE & 208 & 69.33 \\
\hline MALE & 92 & 31 \\
\hline Total & 300 & 100 \\
\hline
\end{tabular}

Table 2: Type, management, frequency and percentage of orthodontic emergencies in study

\begin{tabular}{|l|l|l|l|}
\hline Emergency type & Management & $\begin{array}{l}\text { Frequency of } \\
\text { presentation }\end{array}$ & $\begin{array}{l}\text { Percentage } \\
\text { of total } \\
\text { presentation }\end{array}$ \\
\hline Poking wires & Cut it with cutter & 30 & $10 \%$ \\
\hline Broken fixed retainer & No treatment & 3 & $1 \%$ \\
\hline Loose bracket & $\begin{array}{l}\text { Leave it as it is or } \\
\text { remove it }\end{array}$ & 156 & $52 \%$ \\
\hline Loose band & Remove it & 34 & $11.3 \%$ \\
\hline Exposed ligature tie & Cut it with cutter & 12 & $4 \%$ \\
\hline Fractured power chain & No treatment & 19 & $6.3 \%$ \\
\hline Loose separator & No treatment & 22 & $7.3 \%$ \\
\hline $\begin{array}{l}\text { Broken appliances } \\
\text { (TPA /NANCE) }\end{array}$ & Remove it & 15 & $5 \%$ \\
\hline $\begin{array}{l}\text { Loose removable } \\
\text { appliances }\end{array}$ & Do not wear it & 2 & $0.6 \%$ \\
\hline Loose mini-implants & Remove it & 7 & $2.3 \%$ \\
\hline
\end{tabular}

majority of the responders were from the age group of 18-30 years with the mean ages were $27 \pm 3.5$ years for females and $19 \pm 2.22$ years for males. The highest numbers of 
Pervez H/ Siddiqui MK/ Sattar A/ Sultan H/ Khan T/ Haqqui R
At-home management strategies adopted by orthodontic patients during COVID-19 related closure of orthodontic clinics complications reported during the lockdown period were loose brackets, loose bands and poking of archwire. The most common at-home hack used was removing the loose bracket/ bands and cutting of free end of archwire with nail cutter like instrument. (Table 2) The majority of the participants did not respond to complications and waited for the reopening or resumption of orthodontic services. Binomial test was applied to find the correlation between males and females regarding the complications associated orthodontic treatment. (Table 3) Compared to males, females face more problems related to ongoing fixed orthodontic

Table 3: Most common emergency reported during lockdown and their distribution among gender

\begin{tabular}{|l|l|l|l|}
\hline $\begin{array}{l}\text { MOST COMMON } \\
\text { EMERGENCIES }\end{array}$ & Male & Female & P value \\
\hline Loose bracket & 60 & 96 & $0.00^{*}$ \\
\hline Loose band & 15 & 19 & $0.00^{*}$ \\
\hline Poking wires & 6 & 24 & $0.00^{*}$ \\
\hline
\end{tabular}

Chi-square test

* $\mathrm{P}<0.05$ is significant

treatment. It was seen that males on an average have more awareness about tackling the complications related to orthodontic treatment as compared to females.

\section{DISCUSSION}

As we know that the treatment duration of orthodontic treatment is roughly around 12-18 months. ${ }^{7}$ In case of closure of orthodontic offices, treatment can get prolonged and emergencies like loose brackets, loose bands, poking arch-wires etc. are more likely to occur. To manage such emergencies, patients should have adequate knowledge before dealing with it.

The most common complication presented by the current orthodontic patients during lockdown was loose brackets. In the majority of cases, it was left as it is. Some patients removed it with a tweezer. This is in accordance with the article published by Caprioglio in 2020, where he mentioned loose bracket as the most frequent complication. ${ }^{8}$ The next problem reported by the patient was loose bands. Nearly, all the patients removed it and kept it for future visits. Some of the bands patients brought to the clinic was broken, so new bands were issued.

In the case of poking wires or impinging of bracket hook, orthowax is a good temporary solution. It is recommended to give a box of orthodontic relief wax right at the start of orthodontic treatment in a normal scenario. ${ }^{9}$ During lockdown; it can be purchased from drug stores or pharmacies which are more likely to be opened as they are considered as an essential service during pandemics. In case of not having access to the stores, some online services like
Amazon also offer delivery service right at the doorstep. ${ }^{8}$

Patients who were not able to reposition the wire, the best option given to them was to cut it with a nail clipper. They were also informed about the disinfection of the nail clipper which is boiling the instrument in $100{ }^{\circ} \mathrm{C}$ water for 30 min. $^{10}$

Broken removable appliances was something patients cannot do anything about it. So, they were informed that keep the broken appliance in a safe place and bring them on their next possible appointment so that they can be repaired. In the case of lost appliances, patients were informed about the charges required in the construction of a new appliance once services are restored.

The most effective way to deal with emergencies is through social media applications like Whatsapp. ${ }^{8}$ Nearly, all patients had access to smartphones and all of them use WhatsApp. Patients were told to upload their pictures, videos and instructions were then given to them via WhatsApp service. This type of service is well corroborated by the author Thimbleby who stated virtual assistance as the future of health services. ${ }^{11}$ Not only the clinicians but also the patients should be fully equipped with these technologies to meet the challenges in the future. ${ }^{11}$ With the introduction of these smart technologies, it will make health care services more effective, convenient and personalized. ${ }^{12}$

\section{CONCLUSION}

It is the responsibility of the clinician to keep in touch with their patients during pandemic like situation through telemedicine portal. In case of emergencies, patients should be provided with an adequate amount of information to tackle any complications with ease and without hurting themselves. Males reported less complication during pandemic related closure of orthodontic offices as compared to females.

\section{FINANCIAL SUPPORT AND SPONSORSHIP}

Nil

\section{CONFLICTS OF INTEREST}

There are no conflicts of interest

\section{REFERENCES}

1. Langade D, Modi PD, Sidhwa YF, et al.: Burnout syndrome among medical practitioners acrossIndia: a questionnaire-based survey. Cureus. 2016, 8:e771. Accessed: March 3, 2020:

https://doi.org/10.7759/cureus.771 
Pervez H/ Siddiqui MK/ Sattar A/ Sultan H/ Khan T/ Haqqui R

2. Cascella M, Rajnik M, Cuomo A, Dulebohn SC, Di Napoli R: Features, Evaluation and Treatment Coronavirus (COVID-19). StatPearls Publishing, Treasure Island, FL; 2020.

3. WHO Director-General's opening remarks at the media briefing on COVID-19 - 11 March 2020. (2020). Accessed: Mar 19, 2020: https://www.who.int/dg/speeches/detail/who-directorgeneral-s-openingremarks-at-the-media-briefing-on-covid-19---11-.

4. Peng X, Xu X, Li Y, Cheng L, Zhou X, Ren B. Transmission routes of 2019- nCoV and controls in dental practice. Int J Oral Sci. 2020; 12:1-6.

https://doi.org/10.1038/s41368-020-0075-9

5. Information for healthcare professionals. (2020). Accessed: March 19, 2020. https://www.cdc.gov/coronavirus/2019-ncov/hcp/index.html.

6. Popat H, Thomas K, Farnell DJ. Management of orthodontic emergencies in primary care - self-reported confidence of general dental practitioners. Br Dent J. 2016; 221:21-4.

https://doi.org/10.1038/sj.bdj.2016.495

7. Shrestha, Sandhya \& Shrestha, Lipika \& Shrestha, Namita \& Shrestha, Rabindra. Effect of Orthodontic Treatment in Occurrence of Dental Caries. Orthodo J Nepal.2013;3:31-6.

https://doi.org/10.3126/ojn.v3i1.9279
At-home management strategies adopted by orthodontic patients during COVID-19 related closure of orthodontic clinics

8. Caprioglio A, Pizzetti GB, Zecca PA, Fastuca R, Maino G, Nanda R. Management of orthodontic emergencies during 2019-NCOV. Prog Orthod. 2020; 21:10 (1-4). https://doi.org/10.1186/s40510-020-00310-y

9. Kluemper GT, Hiser DG, Rayens MK, Jay MJ. Efficacy of a wax containing benzocaine in the relief of oral mucosal pain caused by orthodontic appliances. Am J Orthod Dentofal Orthop. 2002; 122: 359-65.

https://doi.org/10.1067/mod.2002.126405

10. Rutala WA, Weber DJ, the Healthcare Infection Control Practices Advisory Committee (HICPAC). Guideline for disinfection and sterilization in healthcare facilities. (2008 (Update: May 2019)).

11. Thimbleby H. Technology and the future of healthcare. J Public Health Res. 2013;2:e28.

https://doi.org/10.4081/jphr.2013.e28

12. ShuoTian,WenboYang, Jehane Michael, LeGrange. Smart healthcare: making medical care more intelligent Global Health J. 2019;3:62-5.

https://doi.org/10.1016/j.glohj.2019.07.001 